Check for updates

Cite this: RSC Adv., 2017, 7, 36617

Received 3rd May 2017

Accepted 10th July 2017

DOI: $10.1039 / c 7 r a 04986 b$

rsc.li/rsc-advances

\title{
High-performance supercapacitors based on conductive graphene combined with $\mathrm{Ni}(\mathrm{OH})_{2}$ nanoflakes
}

\begin{abstract}
Hui Chai, (D) ${ }^{a}$ Xiao Peng, ${ }^{a}$ Ting Liu, ${ }^{a}$ Xiaohui Su, ${ }^{a}$ Dianzeng Jia*a and Wanyong Zhou ${ }^{\text {b }}$
A green and facile strategy is reported for the synthesis of a three-dimensional (3D) graphene nanosheets (GNS)/Ni(OH) 2 composite for use as a supercapacitor material. During this process, graphene oxide was reduced to graphene and $\mathrm{Ni}(\mathrm{OH})_{2}$ was attached in it to form the $\mathrm{GNS} / \mathrm{Ni}(\mathrm{OH})_{2}$ composite via a chemical precipitation route without any complicated procedures. The product was characterized by $\mathrm{X}$-ray diffraction (XRD) and scanning electron microscopy (SEM). The analyses indicated that the $\mathrm{Ni}(\mathrm{OH})_{2}$ sheets were well interwoven on the surfaces of the graphene nanosheets. Furthermore, the composite was electrochemically tested by cyclic voltammetry, galvanostatic charge/discharge, specific capacitance, and by assessing its cycle life. The $\mathrm{GNS} / \mathrm{Ni}(\mathrm{OH})_{2}$ composite exhibited a high specific supercapacitance of $2053 \mathrm{~F} \mathrm{~g}^{-1}$ at a current density of $0.3 \mathrm{~A} \mathrm{~g}^{-1}$ in $6 \mathrm{M} \mathrm{KOH}$ electrolyte and a long cycle life, along with $97 \%$ specific capacitance remaining after 1000 cycles. The GNS/Ni(OH$)_{2}$ composite had superb electrochemical performance compared to bare $\mathrm{Ni}(\mathrm{OH})_{2}$, which could be attributed to its architecture. These results suggest that the $\mathrm{GNS} / \mathrm{Ni}(\mathrm{OH})_{2}$ composite could have potential application as a supercapacitor material.
\end{abstract}

\section{Introduction}

Supercapacitors, also known as electrochemical capacitors (ECs), are considered as one of the most promising and reliable power sources for energy storage devices due to their high power density, long lifetime, quick charging capacity, and environmental friendliness. ${ }^{\mathbf{1 - 4}}$ The energy storage mechanisms of ECs are usually grouped into two types: electrical double-layer capacitance and pseudocapacitance. ${ }^{5,6}$ Commonly, electrochemical pseudocapacitors with high power, high energy, and long lifetimes can fill the gap between batteries, which provide a higher energy density through the faradic reactions of the electroactive materials, and conventional electrolytic capacitors, which can deliver high power at the cost of low energy storage. $^{7-9}$

Electrode materials play a key role in supercapacitors, and mainly consist of three types: carbon, ${ }^{\mathbf{1 0 - 1 3}}$ transition metal oxides, ${ }^{14,15}$ and conducting polymers. ${ }^{16,17}$ Carbonaceous materials are widely used for electrical double-layer capacitors (EDLCs), while metal oxides/hydroxides and conducting polymers are widely used for pseudocapacitors. ${ }^{18,19}$ In recent years,

${ }^{a}$ Key Laboratory of Energy Material, Ministry of Education, Key Laboratory of Advanced Functional Materials, Autonomous Region, Institute of Applied Chemistry, Xinjiang University, Urumqi 830046, Xinjiang, P. R. China. E-mail: huichmails@ 163.com; jdz0991@gmail.com; Fax: +86991858 8883; Tel: +86 9918583083

${ }^{b}$ College of Chemistry \& Chemical Engineering, Xinjiang University, Urumqi 830046, Xinjiang, P. R. China the growing interest in developing alternative pseudocapacitor electrode materials has created many new approaches, such as metal oxide materials, including manganese oxide, ${ }^{20}$ cobalt oxide, ${ }^{21,22}$ nickel oxide, ${ }^{23,24}$ and nickel hydroxide. ${ }^{25}$ These are widely utilized as porous or $3 \mathrm{D}$ nanostructures. $\mathrm{Ni}(\mathrm{OH})_{2}$ is one of the most promising materials owing to its low cost, high theoretical capacity, good capacity retention, easy electrolyte penetration, and well-defined electrochemical redox activity. ${ }^{26,27}$ However, some drawbacks still exist with its use, such as poor electrical conductivity and cycle performance caused by volume breakage, and hence more work is needed to improve its electrochemical performance.

Carbon materials possess high electrical conductivity and ductility, which can further improve the capacitive behavior of metal oxide materials and hence these have received much attention by introduction into EC composite electrodes. Graphene $^{28}$ was discovered by Geim et al. in 2004 (ref. 29) and it constitutes a two dimensional (2D) single-layer of carbon sheets, whose atoms are bonded together in a hexagonal $\mathrm{sp}^{2}$ arrangement. ${ }^{30}$ Graphene possesses good conductivity, superior mechanical properties, a large specific surface ratio, and excellent chemical stability in various electrolytes. ${ }^{31-34}$ Due to the above advantages, it was confirmed that graphene has a wide range of potential applications in supercapacitors. Metal oxide/hydroxide and graphene composites as suitable candidate materials for supercapacitors have thus attracted significant research interest. 
In this paper, we report a low-cost strategy to synthesize a 3D $\mathrm{GNS} / \mathrm{Ni}(\mathrm{OH})_{2}$ composite using a facile and rapid chemical precipitation route without any controlling agent. In previous reports, it was reported that the mass loading values of electrodes materials exert an important impact on the electrocapacitive behavior. ${ }^{35}$ Among these electrode materials, the $\mathrm{GNS} / \mathrm{Ni}(\mathrm{OH})_{2}$ composite with $120 \mathrm{mg}$ GO added demonstrated superimposed layers and a 3D porous structure, with a high specific capacitance of $2053 \mathrm{~F} \mathrm{~g}^{-1}$ at $0.3 \mathrm{~A} \mathrm{~g}^{-1}$ when the mass loading value of the electrodes material was $8 \mathrm{mg}$. The synthesized GNS/Ni(OH $)_{2}$ composite displayed excellent electrochemical performance even at a high mass loading. Compared with a pure $\mathrm{Ni}(\mathrm{OH})_{2}$ electrode, it also delivered excellent cycling stability, with $97 \%$ of its pristine specific capacitance retained after 1000 cycles at a current density of $2.5 \mathrm{~A} \mathrm{~g}^{-1}$.

\section{Experimental section}

\subsection{Synthesis of the GNS/Ni(OH $)_{2}$ composite}

Graphene oxide (GO) was synthesized from natural graphite powders by a modified Hummer's method. ${ }^{36}$ Synthesis of the GNS/Ni(OH $)_{2}$ composite was performed via a chemical precipitation method as follows. First, $0.01 \mathrm{~mol}$ of $\mathrm{Ni}\left(\mathrm{NO}_{3}\right)_{2} \cdot 6 \mathrm{H}_{2} \mathrm{O}$ and $0.03 \mathrm{~mol} \mathrm{CO}\left(\mathrm{NH}_{2}\right)_{2}$ were added into $100 \mathrm{~mL}$ distilled water and treated with ultrasonic waves until a transparent liquid was obtained. Then, $40 \mathrm{mg}, 80 \mathrm{mg}$, and $120 \mathrm{mg}$ of GO was respectively added to the above solution and treated with ultrasonic waves until a suspension presented; the mixture was then kept under magnetic stirring at $95{ }^{\circ} \mathrm{C}$ for $16 \mathrm{~h}$ and then cooled to room temperature gradually. Subsequently, the black precipitation was filtered, washed with distilled water and absolute alcohol several times, and dried at $80{ }^{\circ} \mathrm{C}$ for $12 \mathrm{~h}$ in a vacuum oven. At last, the target products of the $\mathrm{Ni}(\mathrm{OH})_{2} / \mathrm{GNS}$ composite were obtained and termed with NG-1, NG-2, and NG-3 separately. For comparison, pure GNS and pure $\mathrm{Ni}(\mathrm{OH})_{2}$ were prepared by the same method.

\subsection{Characterization}

The structure of the product was characterized by X-ray diffraction (XRD, Bruker D8, $\lambda=1.5406 \AA$ ). The morphology and $3 \mathrm{D}$ microstructure of the synthesized composite were observed by scanning electron microscopy (SEM, JSM-6700F, Japan).

\subsection{Electrochemical measurements}

The working electrode was fabricated through mixing the active material, carbon black, and polyfluortetraethylene (PTFE) at a weight ratio of $80: 15: 5$ and then pasted onto nickel foam $(1.0 \mathrm{~cm} \times 1.0 \mathrm{~cm})$. A small amount of ethanol was added to the mixture to form a more homogeneous paste. Then, the working electrode was dried at $80{ }^{\circ} \mathrm{C}$ for $12 \mathrm{~h}$ in a vacuum oven. Each electrode contained about $8 \mathrm{mg}$ of electroactive material. Electrochemical characterization was carried out in a conventional three-electrode cell with $6 \mathrm{M} \mathrm{KOH}$ aqueous solution as the electrolyte. Platinum foil was used as the counter electrode and $\mathrm{Hg} / \mathrm{HgO}$ as the reference electrode. All the electrochemical measurements were conducted using a CHI660 (Shanghai) electrochemical work station.

\section{Results and discussion}

A schematic representation of the formation process of the $\mathrm{GNS} / \mathrm{Ni}(\mathrm{OH})_{2}$ composite is shown in Scheme 1.

First, $\mathrm{CO}\left(\mathrm{NH}_{2}\right)_{2}$ and $\mathrm{Ni}\left(\mathrm{NO}_{3}\right)_{2} \cdot 6 \mathrm{H}_{2} \mathrm{O}$ were sonicated in water to form a transparent and homogeneous solution of $\mathrm{Ni}^{2+}$ ions and released hydroxyl ions slowly, resulting in the formation of $\mathrm{Ni}(\mathrm{OH})_{2}$, as suggested by the following reactions:

$$
\begin{gathered}
\mathrm{CO}\left(\mathrm{NH}_{2}\right)_{2}+3 \mathrm{H}_{2} \mathrm{O} \rightarrow 2 \mathrm{NH}_{4}^{+}+\mathrm{CO}_{2}+2 \mathrm{OH}^{-} \\
\mathrm{Ni}^{2+}+2 \mathrm{OH}^{-} \rightarrow \mathrm{Ni}(\mathrm{OH})_{2}
\end{gathered}
$$

Then, GO was added to the above mixture. Under magnetic stirring and refluxing, GO was reduced to GNS and uniform $\mathrm{Ni}(\mathrm{OH})_{2}$ was recombined on the surface of the graphene platelets, and during this process, the $\mathrm{Ni}(\mathrm{OH})_{2}$ selectively bonded with carboxyl groups through mutual electrostatic attraction. These composite platelets also prohibited the stacking of graphene sheets by van der Waals' force. ${ }^{37,38}$

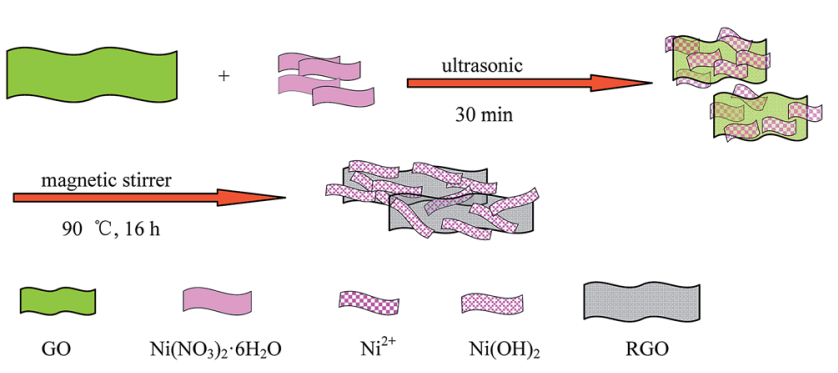

Scheme 1 Schematic illustration of the formation process of the GNS/ $\mathrm{Ni}(\mathrm{OH})_{2}$ composite.

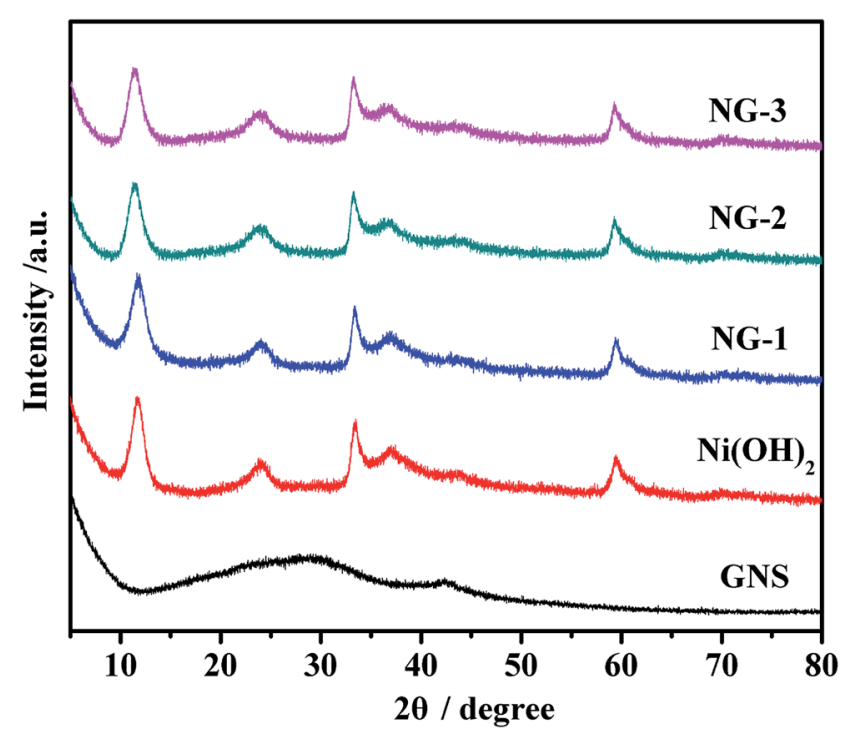

Fig. 1 XRD patterns of the GNS, Ni(OH) $, \mathrm{NG}-1, \mathrm{NG}-2$, and NG-3 composite materials. 

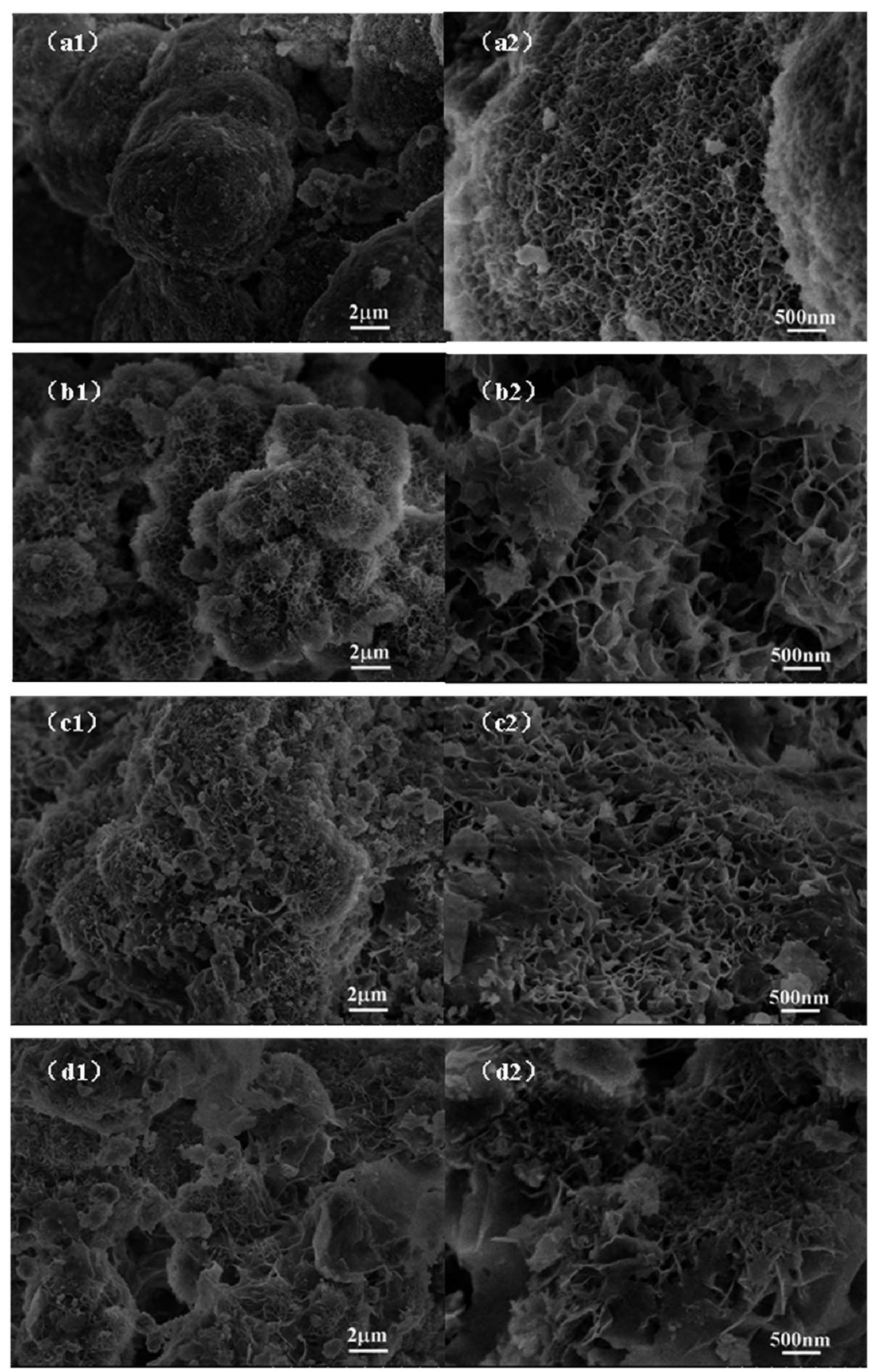

Fig. 2 FESEM images of the Ni(OH) 2 (a), NG-1 (b), NG-2 (c), and NG-3 (d) composite materials.

X-ray diffraction measurements were employed to investigate the phase and crystal structure of the synthesized samples, as shown in Fig. 1. As can be seen in Fig. 1, GNS has two peaks that appear at around $28^{\circ}$, which is in accordance with the reported values and which imply that GO has been reduced to GNS and that the oxygen groups have been removed during the chemical precipitation process. According to the Bragg formula, the calculated interlayer spacing is $0.37 \mathrm{~nm}$. Also form Fig. 1, we can see that $\mathrm{Ni}(\mathrm{OH})_{2}$ shows well-defined peaks centered at $11.9^{\circ}, 24.2^{\circ}, 33.4^{\circ}, 35.7^{\circ}$, and $59.6^{\circ}$, corresponding to the (003) (006), (101), (012), and (110) crystal planes of a-Ni(OH $)_{2}$, respectively. All the peak positions of $\mathrm{Ni}(\mathrm{OH})_{2}$ are consistent with the single phase a-Ni(OH $)_{2}$ with a rhombohedral structure (JCPDS no. 38-0715) ${ }^{39}$ and no other impurity peaks were detected. In addition, the XRD patterns of NG-1, NG-2, and NG-3 were similar to bare $\mathrm{Ni}(\mathrm{OH})_{2}$, which perhaps indicates that GNS has almost no impact on the pore regularity of $\mathrm{Ni}(\mathrm{OH})_{2}$. Due to the $\mathrm{Ni}(\mathrm{OH})_{2}$ even being attached to the surface of GNS nanosheets, the characteristics peaks of GNS are not obvious in the composite diffraction spectra pattern.

The field emission scanning electron microscopy (FESEM) images of graphene are shown in Fig. 3. The bare $\mathrm{Ni}(\mathrm{OH})_{2}$ 


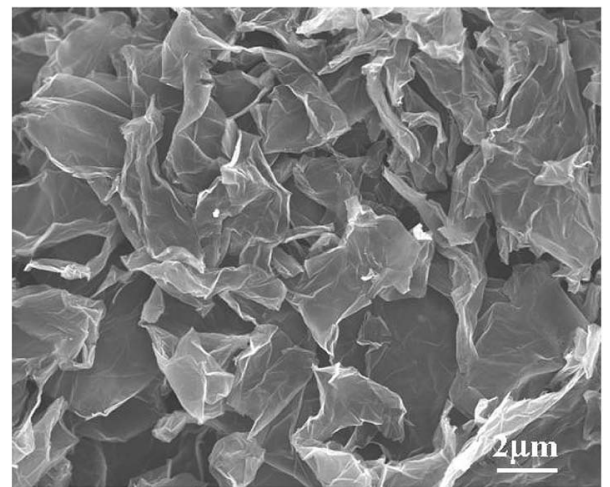

Fig. 3 FESEM image of graphene.

(Fig. 2a1 and a2) show a rough surface sphere nanostructure, with the nanostructures stacked atop each other. After combining with graphene, the GNS/ $\mathrm{Ni}(\mathrm{OH})_{2}$ composite clearly shows a 3D hierarchical porous structure. Fig. $2 \mathrm{~b} 1$ and b2 illustrate the NG-1 composite has an obvious nanoflake structure, which has a tendency to reunite at the center. Along with the increasing percentage of graphene content, the NG-2 composite (Fig. 2c1 and $\mathrm{c} 2$ ) has an obvious layer structure and porosity. The samples of NG-3 (Fig. $2 \mathrm{~d} 1$ and $\mathrm{d} 2$ ) clearly show the superimposed layers, which form 3D porous nanosheets. According to the electrochemical performance mentioned later, the reason for the GNS/Ni(OH) ${ }_{2}$ composite (NG-3) delivering the best capacitive behavior among these products may be related to its superimposed layers and 3D porous nanosheets structure, which offer numerous electroactive sites for effective electron/ ion transport, thus leading to excellent electrochemical performance.

The electrochemical properties of the samples were characterized by cyclic voltammogram (CV), galvanostatic charge/ discharge, specific capacitance and cycle life measurements. All the measurements were carried out in a three-electrode system with $\mathrm{Hg} / \mathrm{HgO}$ (in $6 \mathrm{M} \mathrm{KOH}$ ) as the reference electrode. Fig. 4 shows the CV curves of pure $\mathrm{Ni}(\mathrm{OH})_{2}, \mathrm{NG}-1, \mathrm{NG}-2$, and NG-

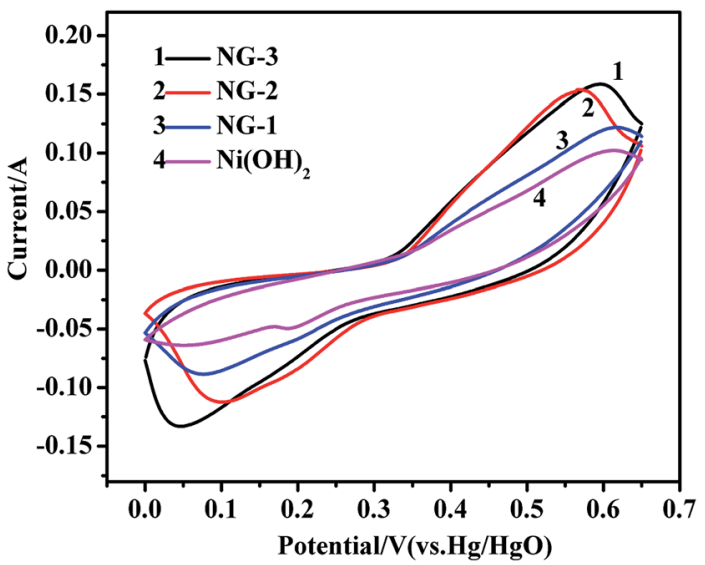

Fig. 4 CV curves of the Ni(OH) $2, N G-1, N G-2$, and NG-3 composite materials at a scan rate of $5 \mathrm{mV} \mathrm{s}^{-1}$.

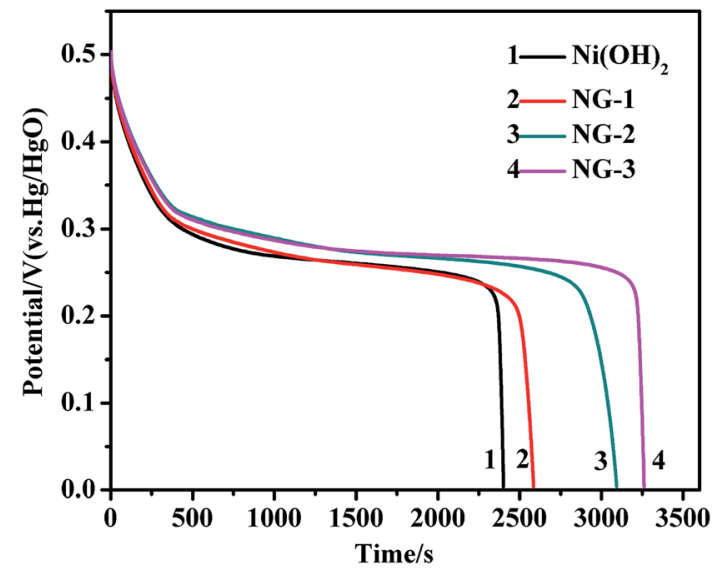

Fig. 5 The galvanostatic discharge curves of the $\mathrm{Ni}(\mathrm{OH})_{2}, \mathrm{NG}-1, \mathrm{NG}-2$, and NG-3 composite materials at a current density of $0.3 \mathrm{~A} \mathrm{~g}^{-1}$.

3 composite materials electrode with the potential varying from 0 to $0.65 \mathrm{~V}$ at a scan rate of $5 \mathrm{mV} \mathrm{s}^{-1}$. The $\mathrm{CV}$ curve of pure $\mathrm{Ni}(\mathrm{OH})_{2}$ is apparently narrower and has lower redox peaks than that of the GNS/Ni(OH $)_{2}$ composites at the same scan rate, indicating the smaller specific capacitances and poor reversibility. With the increase in GNS content, the cyclic voltammetry curve showed obvious redox peaks, good symmetry, and large specific capacitances. It can be interpreted that the introduction of GNS increases the capacitance value, mainly through increasing the conductivity of the $\mathrm{Ni}(\mathrm{OH})_{2}$. The redox peaks observed in the CV curve of $\mathrm{Ni}(\mathrm{OH})_{2}$ were due to the following Faradaic reactions: ${ }^{40,41}$

$$
\alpha-\mathrm{Ni}(\mathrm{OH})_{2}+\mathrm{OH}^{-} \leftrightarrow \gamma-\mathrm{NiOOH}+\mathrm{H}_{2} \mathrm{O}+\mathrm{e}^{-}
$$

During the process, the anodic peak is caused by the oxidation reactions where $\alpha-\mathrm{Ni}(\mathrm{OH})_{2}$ is converted into $\gamma-\mathrm{NiOOH}$, while the cathodic peak is caused by the inverse reduction reaction.

Galvanostatic charge-discharge measurements were performed at a current density of $0.3 \mathrm{~A} \mathrm{~g}^{-1}$. The discharge curves of

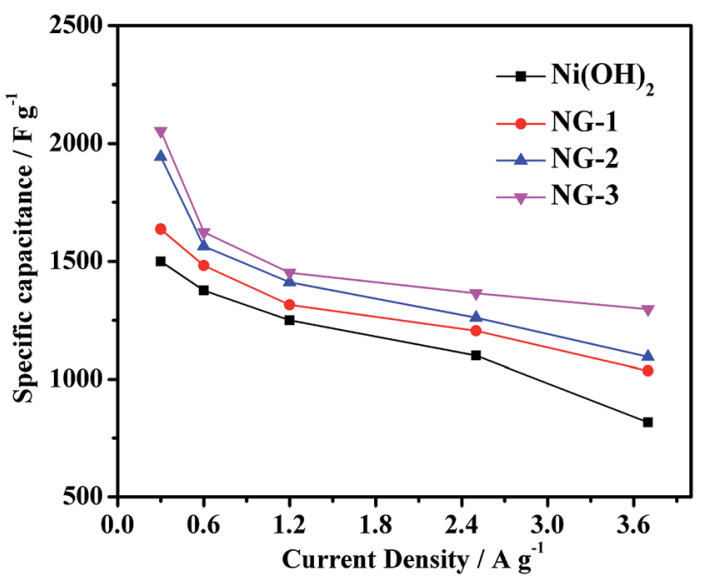

Fig. 6 Specific capacitance of the Ni(OH) $, \mathrm{NG}-1, \mathrm{NG}-2$ and NG-3 composite materials at various current densities. 


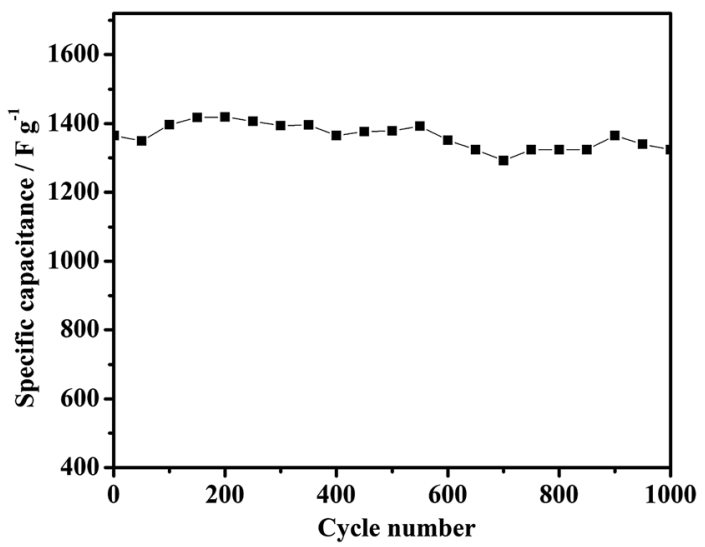

Fig. 7 Cycle life of the NG-3 composite materials.

the $\mathrm{Ni}(\mathrm{OH})_{2}$, NG-1, NG-2, and NG-3 composites are shown in Fig. 5. The specific capacitance was calculated by $C=I \times t /(V=$ $m$ ), where $C$ is the specific capacitance, $I$ is the discharging current, $t$ is the discharge time, $V$ is the potential drop during discharge, and $m$ is the mass of the active material in a single electrode. The specific capacitance values of the $\mathrm{Ni}(\mathrm{OH})_{2}, \mathrm{NG}-1$, NG-2, and NG-3 composite electrode were $1500 \mathrm{~F} \mathrm{~g}^{-1}, 1637 \mathrm{~F}$ $\mathrm{g}^{-1}, 1944 \mathrm{~F} \mathrm{~g}^{-1}$, and $2053 \mathrm{~F} \mathrm{~g}^{-1}$, respectively. These results were consistent with the cyclic voltammetry tests, where the specific capacitance of the composites as electrode material was higher than that of bare $\mathrm{Ni}(\mathrm{OH})_{2}$, with the NG-3 composite having the highest specific capacitance, which indicate that GNS can act as a highly conductive medium, providing much more flexible layers with an enlarged interlayer space and increased surface area, thus benefiting the electrochemical performance of the composite. ${ }^{37}$ Moreover, the improved specific capacitance was attributed to the $3 \mathrm{D}$ loose structure of the composite, which provides more active sites for the redox reaction of the active materials and more interfacial contact with the electrolyte, thus facilitating fast electron transfer between the active materials and the charge collector, leading to fast electron and ion transmission to the electrode. .2,43 $^{4}$

The current density was varied and the obtained specific capacitances at different current densities are shown in Fig. 6. It can be seen that the specific capacitance decreases with the increase in the current densities ranging from 0.3 to $3.7 \mathrm{~A} \mathrm{~g}^{-1}$, and the capacitance of the NG-3 composite is always higher than that of the pure $\mathrm{Ni}(\mathrm{OH})_{2}$, NG-1, and NG-2. At the current density of $3.7 \mathrm{~A} \mathrm{~g}^{-1}$, the specific capacitance of NG-3 (1297 F $\mathrm{g}^{-1}$ ) was $95 \%$ of that of at current density of $2.5 \mathrm{~A} \mathrm{~g}^{-1}$, while $\mathrm{Ni}(\mathrm{OH})_{2}$, NG-1, and NG-2 were $74 \%, 85 \%$, and $87 \%$, respectively. It can be interpreted that the electrical conductivity is closely associated with the porous channels. These porous channels provide more effective contact between the active materials and the electrolyte in sample NG-3, which leads to its outstanding electrochemical property and good rate performance.

The cycle life is another important factor for supercapacitor electrode materials. Fig. 7 shows the cyclability of the NG-3 composite over 1000 cycles between 0 and $0.5 \mathrm{~V}$ at a discharge current density of $2.5 \mathrm{~A} \mathrm{~g}^{-1}$. Evidently, after 150 cycles, the utilization of active material reached the highest level and the specific capacitance reaches its highest level with the electrolyte gradually being penetrated. The lowest specific capacitance after 1000 cycles still retains $97 \%$ of the maximum capacitance, which is higher than that for pure $\mathrm{Ni}(\mathrm{OH})_{2}\left(1377 \mathrm{~F} \mathrm{~g}^{-1}\right.$ with $63 \%)$. The cycling test suggests that the NG-3 composite electrode has high stability for long-term applications. The excellent capacitive behavior of the psuedocapacitor most likely arises from both a good synergistic effect between GNS and $\mathrm{Ni}(\mathrm{OH})_{2}$ and the electric conductivity of the hierarchically porous structure, which yields an aggregation-free NG-3 composite, prompts the redox reaction to be more effective at the GNS/ $\mathrm{Ni}(\mathrm{OH})_{2}$ electrode surface and electrolyte interface, and facilitates effective charge transport as well as maintaining the mechanical integrity of the overall electrode for fast energy storage and delivery.

In comparison with the other results listed in Table 1, the asprepared $\mathrm{GNS} / \mathrm{Ni}(\mathrm{OH})_{2}$ delivers an excellent specific capacitance even at a high mass loading, which gives rise to the potential for these materials to serve as new and attractive active materials for wide application in supercapacitors.

\section{Conclusions}

In this work, we developed a hierarchically porous $\mathrm{GNS} / \mathrm{Ni}(\mathrm{OH})_{2}$ composite and demonstrated the composite as a promising electrode material for high-performance pseudocapacitors with good electrochemical performance and long cycle life. The overall electrochemical performance of the composite was drastically improved compared to bare $\mathrm{Ni}(\mathrm{OH})_{2}$ and graphene. The excellent capacitive performances result from the

Table 1 Electrochemical performance comparison between some electrodes. Complete data can be found in the references

\begin{tabular}{|c|c|c|c|c|c|}
\hline Electrode & Specific capacitance & Capacitance retention & $\begin{array}{l}\text { Electroactive } \\
\text { material }\end{array}$ & Electrolyte & Ref. \\
\hline$\alpha-\mathrm{Ni}(\mathrm{OH})_{2} /$ graphite & $1956 \mathrm{~F} \mathrm{~g}^{-1}\left(1 \mathrm{~A} \mathrm{~g}^{-1}\right)$ & $70 \%\left(10 \mathrm{~A} \mathrm{~g}^{-1}, 1000\right.$ cycles $)$ & & $\mathrm{KOH}(6 \mathrm{M})$ & 39 \\
\hline$\alpha-\mathrm{Ni}(\mathrm{OH})_{2} / \mathrm{rGO}$ & $521 \mathrm{~F} \mathrm{~g}^{-1}\left(50 \mathrm{mV} \mathrm{s}^{-1}\right)$ & $87.9 \%\left(50 \mathrm{mV} \mathrm{s}^{-1}, 1000\right.$ cycles $)$ & & $\mathrm{KOH}(6 \mathrm{M})$ & 44 \\
\hline $\mathrm{Ni}(\mathrm{OH})_{2} /$ graphene & $166 \mathrm{~F} \mathrm{~g}^{-1}\left(0.5 \mathrm{~A} \mathrm{~g}^{-1}\right)$ & $65 \%\left(10 \mathrm{~A} \mathrm{~g}^{-1}, 1000\right.$ cycles $)$ & & KOH (6 M) & 45 \\
\hline $3 \mathrm{D}$ graphene $/ \mathrm{Ni}(\mathrm{OH})_{2}$ & $718.2 \mathrm{~F} \mathrm{~g}^{-1}\left(6.7 \mathrm{~A} \mathrm{~g}^{-1}\right)$ & $84.2 \%\left(10 \mathrm{~A} \mathrm{~g}^{-1}, 500\right.$ cycles $)$ & $1 \mathrm{mg}$ & $\mathrm{KOH}(6 \mathrm{M})$ & 46 \\
\hline graphene $/ \mathrm{Ni}(\mathrm{OH})_{2}$ & $1247 \mathrm{~F} \mathrm{~g}^{-1}\left(5 \mathrm{mV} \mathrm{s}^{-1}\right)$ & $95 \%$ (16 $\mathrm{A} \mathrm{g}^{-1}, 2000$ cycles $)$ & $5 \mathrm{mg}$ & $\mathrm{KOH}(6 \mathrm{M})$ & 47 \\
\hline$\left(\mathrm{Ni}(\mathrm{OH})_{2} / \mathrm{rGO}\right.$ & $1886 \mathrm{~F} \mathrm{~g}^{-1}\left(5 \mathrm{~A} \mathrm{~g}^{-1}\right)$ & $70 \%\left(10 \mathrm{~A} \mathrm{~g}^{-1}, 1000\right.$ cycles $)$ & & КOH (3 M) & 48 \\
\hline $\mathrm{GNS} / \mathrm{Ni}(\mathrm{OH})_{2}$ & $1985.1 \mathrm{~F} \mathrm{~g}^{-1}\left(5 \mathrm{~mA} \mathrm{~cm}{ }^{-2}\right)$ & $93.5 \%\left(30 \mathrm{~mA} \mathrm{~cm}{ }^{-2}, 500\right.$ cycles $)$ & $6 \mathrm{mg}$ & KOH (6 M) & 49 \\
\hline Our GNS/Ni(OH $)_{2}$ & $2053 \mathrm{~F} \mathrm{~g}^{-1}\left(0.3 \mathrm{~A} \mathrm{~g}^{-1}\right)$ & $97 \%\left(2.5 \mathrm{~A} \mathrm{~g}^{-1}, 1000\right.$ cycles $)$ & $8 \mathrm{mg}$ & KOH $(6 \mathrm{M})$ & Ours \\
\hline
\end{tabular}


incorporation of nanoflake pseudocapacitive $\mathrm{Ni}(\mathrm{OH})_{2}$ into a three-dimensional graphene network. The porous structure facilitates excellent electronic/ionic conductivity and large interfaces between active materials and electrolyte, which takes full advantage of the pseudocapacitance of $\mathrm{Ni}(\mathrm{OH})_{2}$ and the conductivity of GNS. In addition, the porous network obviously improves the mechanical rigidity and electrochemical stability of the GNS/Ni(OH $)_{2}$. Therefore, the specific capacitance of the composite is improved, which makes it a promising electrode material for high-performance alkaline rechargeable supercapacitors.

\section{Acknowledgements}

This work was supported by Natural Science Foundation of Xinjiang Uygur Autonomous Region (No. 2015211c250).

\section{References}

1 Y. Wang and Y. Xia, Adv. Mater., 2013, 25, 5336.

2 C. Z. Yuan, B. Gao, L. F. Shen, S. D. Yang, L. Hao, X. J. Lu, F. Zhang, L. J. Zhang and X. G. Zhang, Nanoscale, 2011, 3, 529.

3 O. Y. Tian, K. Cheng, F. Yang, L. M. Zhou, K. Zhu, K. Ye, G. L. Wang and D. X. Cao, J. Mater. Chem. A, 2017, 5, 14551. 4 H. N. Jia, J. H. Lin, Y. L. Liu, S. L. Chen, Y. F. Cai, J. L. Qi, J. C. Feng and W. D. Fei, J. Mater. Chem. A, 2017, 5, 10678.

5 C. Liu, F. Li, L. P. Ma and H. M. Cheng, Adv. Mater., 2010, 22, E28.

6 D. Choi, G. E. Blomgren and P. N. Kumta, Adv. Mater., 2006, 18, 1178.

7 M. S. Javed, J. Chen, L. Chen, Y. Xi, C. L. Zhang, B. Y. Wan and C. G. Hu, J. Mater. Chem. A, 2016, 4, 667.

8 X. Y. Lang, A. Hirata, T. Fujita and M. W. Chen, Adv. Energy Mater., 2014, 4, 1301809.

9 G. Wang, L. Zhang and J. Zhang, Chem. Soc. Rev., 2012, 41, 797.

10 Q. Q. Zhou, X. Y. Chen and B. Wang, Microporous Mesoporous Mater., 2012, 158, 155.

11 X. Y. Chen and Q. Q. Zhou, Electrochim. Acta, 2012, 71, 92. 12 Y. Huang, J. J. Liang and Y. S. Chen, Small, 2012, 8, 1805.

13 C. Zheng, W. Z. Qian, C. J. Cui, Q. Zhang, Y. G. Jin, M. Q. Zhao, P. H. Tan and F. Wei, Carbon, 2012, 50, 5167.

14 J. P. Liu, J. Jiang, C. W. Cheng, H. X. Li, J. X. Zhang, H. Gong and H. J. Fan, Adv. Mater., 2011, 23, 2076.

15 R. Z. Li, X. Ren, F. Zhang, C. Du and J. P. Liu, Chem. Commun., 2012, 48, 5010.

16 H. R. Ghenaatian, M. F. Mousavi and M. S. Rahmanifar, Electrochim. Acta, 2012, 78, 212.

17 R. B. Rakhi, W. Chen and H. N. Alshareef, J. Mater. Chem., 2012, 22, 5177.

18 L. L. Zhang and X. S. Zhao, Chem. Soc. Rev., 2009, 38, 2520.

19 G. Wang, L. Zhang and J. Zhang, Chem. Soc. Rev., 2012, 41, 797.

20 X. H. Yang, Y. G. Wang, H. M. Xiong and Y. Y. Xia, Electrochim. Acta, 2007, 53, 752.
21 S. Xiong, C. Yuan, X. Zhang, B. Xi and Y. Qian, Chem.-Eur. J., 2009, 15, 5320.

22 X. Xia, J. Tu, Y. Mai, X. Wang, C. Gu and X. Zhao, J. Mater. Chem., 2011, 21, 9319.

23 C. Yuan, X. Zhang, L. Su, B. Gao and L. Shen, J. Mater. Chem., 2009, 19, 5772.

24 W. Wen, J. M. Wu and M. H. Cao, Nano Energy, 2013, 2, 1383.

25 L. Cao, L. B. Kong, Y. Y. Liang and H. L. Li, Adv. Mater., 2004, 16, 1853.

26 H. L. Wang, H. S. Casalongue, Y. Y. Liang and H. J. Dai, J. Am. Chem. Soc., 2010, 132, 7472.

27 L. Wang, X. Li, T. Guo, X. Yan and B. K. Tay, Int. J. Hydrogen Energy, 2014, 39, 7876.

28 H. Wang, C. M. Holt, Z. Li, X. Tan, B. S. Amirkhiz, Z. Xu, B. C. Olsen, T. Stephenson and D. Mitlin, Nano Res., 2012, 5, 605.

29 K. S. Novoselov, A. K. Geim, S. V. Morozov, D. Jiang, Y. Zhang, S. V. Dubonos, I. V. Grigorieva and A. A. Firsov, Science, 2004, 306, 666.

30 X. F. Gao, J. Jiang and S. Nagas, J. Phys. Chem. C, 2010, 114, 832.

31 D. Chen, L. Tang and J. Li, Chem. Soc. Rev., 2010, 39, 3157. 32 M. Pumera, Energy Environ. Sci., 2011, 4, 668.

33 Y. Sun, Q. Wu and G. Shi, Energy Environ. Sci., 2011, 4, 1113. 34 L. S. Zhang, L. Y. Jiang, H. J. Yan, W. D. Wang, W. Wang, W. G. Song, Y. G. Guo and L. J. Wan, J. Mater. Chem., 2010, 20, 5462 .

35 X. C. Li, J. J. Shen, W. Sun, X. D. Hong, R. T. Wang, X. H. Zhao and X. B. Yan, J. Mater. Chem. A, 2015, 3, 13244.

36 W. S. Hummers and R. E. Offeman, J. Am. Chem. Soc., 1958, 80, 1339.

37 T. Liu, H. Chai, D. Jia, Y. Su, T. Wang and W. Zhou, Electrochim. Acta, 2015, 180, 998.

38 X. Su, H. Chai, D. Jia, S. J. Bao, W. Y. Wan and M. L. Zhou, New J. Chem., 2013, 37, 439.

39 J. T. Zhang, S. Liu, G. L. Pan, G. R. Li and X. P. Gao, J. Mater. Chem. A, 2014, 2, 1524.

40 S. Yang, X. Wu and C. Chen, Chem. Commun., 2012, 48, 2773. 41 A. Ning, Y. An, Z. Hu, B. Guo, Y. Yang and Z. Lei, J. Mater. Chem. A, 2015, 3, 22239.

42 J. Yan, T. Wei, W. M. Qiao, B. Shao, Q. K. Zhao, L. J. Zhang and Z. J. Fan, Electrochim. Acta, 2010, 55, 6973.

43 Z. J. Fan, J. Yan, T. Wei, L. J. Zhi, G. Q. Ning, T. Y. Li and F. Wei, Adv. Funct. Mater., 2011, 21, 2366.

44 J. W. Lee, T. Ahn, D. Soundararajan, J. M. Ko and J. D. Kim, Chem. Commun., 2011, 47, 6305.

45 J. Y. Ji, L. L. Zhang, H. X. Ji, Y. Li, X. Zhao, X. Bai, X. B. Fan, F. B. Zhang and R. S. Ruoff, ACS Nano, 2013, 7, 6237.

46 C. H. Jiang, B. B. Zhan, C. Li, W. Huang and X. C. Dong, RSC $A d v ., 2014$, 4, 18080.

47 Y. X. Xu, X. Q. Huang, Z. Y. Lin, X. Zhong, Y. Huang and X. F. Duan, Nano Res., 2013, 6(1), 65.

48 X. X. Zang, C. C. Sun, Z. Y. Dai, J. Yang and X. C. Dong, J. Alloys Compd., 2017, 691, 144.

49 H. J. Yan, J. W. Bai, J. Wang, X. Y. Zhang, B. Wang, Q. Liu and L. H. Liu, CrystEngComm, 2013, 15, 10007. 